\title{
Nickel-Catalyzed Reductive Coupling of Unactivated Alkyl Bro- mides and Aliphatic Aldehydes
}

\author{
Cole L. Cruz and John Montgomery*
}

Department of Chemistry, University of Michigan, 930 North University Avenue, Ann Arbor, Michigan, 48108-1055, United States

ABSTRACT: We report the development of a mild, convenient coupling of aliphatic aldehydes and unactivated alkyl bromides. The catalytic system features the use of a common Ni(II) precatalyst and a readily available bisoxazoline ligand and affords silyl-protected secondary alcohols. The reaction is operationally simple, utilizing Mn as a stoichiometric reductant, and tolerates a wide range of functional groups. Initial mechanistic experiments support a mechanism featuring an alpha-silyloxy Ni species which undergoes formal oxidative addition of the alkyl bromide species via a reductive cross-coupling pathway.

The coupling of carbonyl compounds and carbon-nucleophiles is of broad interest to the chemical community to build molecular complexity. The most ubiquitous methods are perhaps the Grignard and related Barbier-type reactions that transform organohalide coupling partners into suitable organometallic nucleophiles. However, the need to pre-generate highly reactive organometallic intermediates is undesirable from a functional group compatibility standpoint, and is occasionally non-trivial, especially on small scales relevant for high-throughput experimentation. ${ }^{1-3}$ While Barbier-type conditions allow for in-situ generation of organometallic nucleophiles, these are generally restricted to activated allylic or propargylic halides.

An especially appealing strategy for introducing Grignard-type couplings to medicinal chemistry efforts is through transition-metal catalysis. These processes are attractive due to the generation of milder nucleophilic partners and higher control of selectivity by tuning the catalytic system and have been employed on process scales. ${ }^{4-6}$ Net reductive couplings using organohalide feedstocks have been developed using stoichiometric reductants to achieve catalytic activity, obviating the need for pre-generation of the organometallic nucleophile. ${ }^{7-13}$ Among the most common systems are $\mathrm{Rh}^{7}, \mathrm{Ni}^{8,11,14,15}$ and $\mathrm{Cr}^{16-21}$-catalyzed couplings of aldehydes and organohalides. Importantly, each of these systems are proposed to proceed via Grignard-type mechanisms, generating organometallic nucleophiles that undergo formal additions to carbonyl electrophiles. $8,11,17,22$ The vast majority of $\mathrm{Ni}$-catalyzed couplings of this type only tolerate aromatic aldehydes and either aryl, allylic or propargylic halides. $8,10,12,13,15,23,24$
Scheme 1. Strategies for Forging C-C Bonds from Aldehydes and Halides.

A) Grignard and Transition-Metal Catalyzed Barbier Couplings

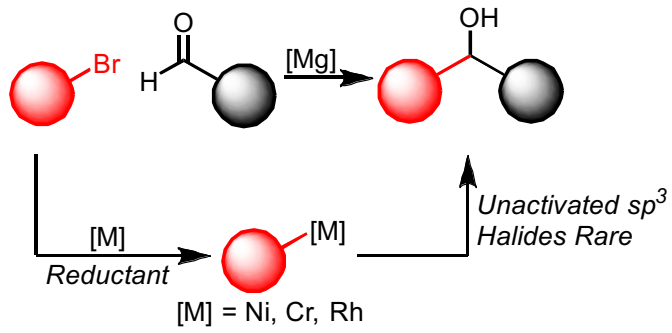

B) Ogoshi - Masked Acyl Anion Equivalents

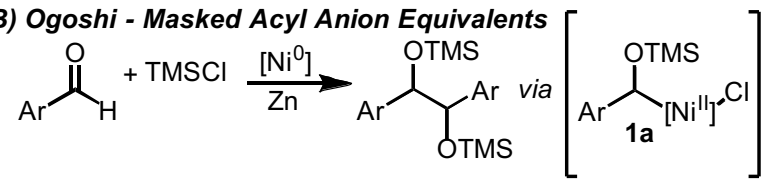

C) This Work

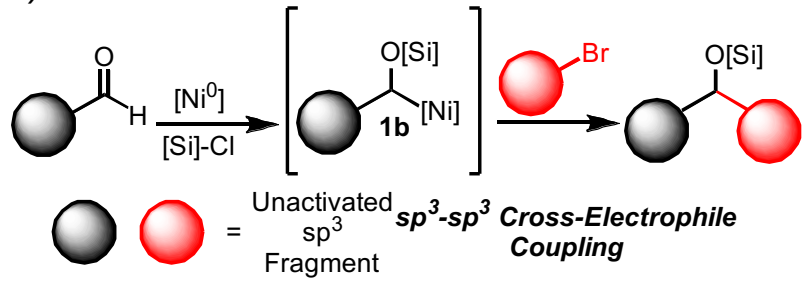

The limitations of existing methods are potentially derived from the involvement of the metalated nucleophilic intermediates involved in these transformations. ${ }^{8,11,22}$ Aliphatic aldehydes are less suitable coupling partners for the organonickel intermediates generated from oxidative addition of aryl halides, as noted by Weix ${ }^{8}$. Additionally, controlling the selective activation and heterocoupling of alkyl halides under reductive conditions is a considerable challenge as homocoupling pathways are often favorable. ${ }^{25-27}$

Due to these challenges a significant gap remains in the development of reductive couplings of aldehydes and alkyl fragments, especially for combinations of aliphatic aldehydes and unactivated $\mathrm{sp}^{3}$ fragments. Cr-catalyzed couplings of alkyl halides (using Co co-catalysis) have been 
demonstrated; however, examples are limited. ${ }^{28 a}$ Alternative coupling partners such as redox-active esters have offered access to similar skeleton frameworks, although similar issues of homocoupling can be encountered.9,10 An electrochemical $\mathrm{Cr}$-catalyzed coupling of redox-active esters and aldehydes has been recently demonstrated by Reisman, Blackmond, and Baran. ${ }^{28 \mathrm{~b}}$ While the scope of the electrochemical process is exceptionally broad, examples with aliphatic halides and aliphatic aldehydes were not illustrated. Key developments from MacMillan similarly provide a broad array of substrate combinations in additions of various bromides to aldehydes through a method that involves acyl radical additions. ${ }^{29}$ This method illustrates rare examples of introducing $\mathrm{sp}^{3}$ alkyl fragments from alkyl bromides to provide products in the ketone oxidation state. Additionally, various feedstocks have been used for the synthesis of ketones in related nickel-catalyzed or NHC-catalyzed processes. ${ }^{30-32}$ Other selective couplings of alkyl organonickel nucleophiles derived from alkyl halides have been described by Martin, and their use has been focused thus far to trapping with electrophiles such as $\mathrm{CO}_{2}$ and isocyanates. ${ }^{33-36}$

Table 1. Optimization of Reaction Parameters. ${ }^{a}$

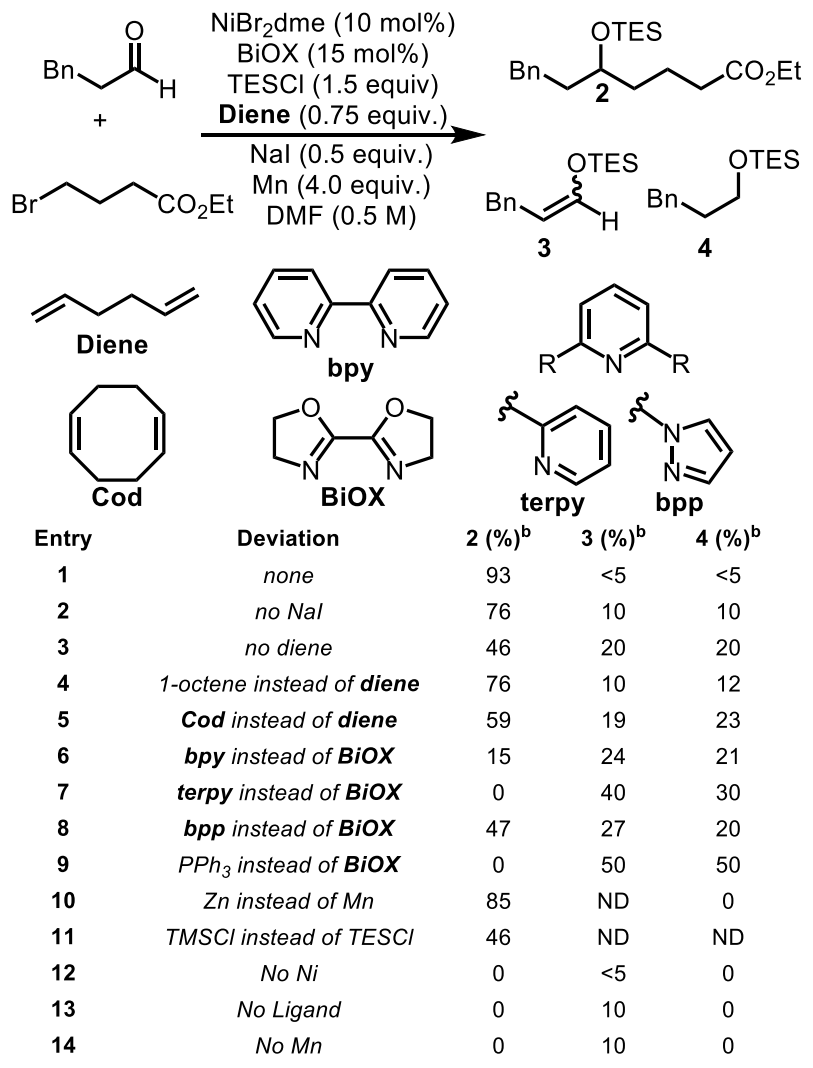

ND = Not Determined a) Unless otherwise stated, reactions were run on a $0.2 \mathrm{mmol}$ scale with respective to the aldehyde substrate and 2.0 equiv. of alkyl bromide. b) Yields were determined either by NMR vs. mesitylene or by GC-FID with 1,3,5-trimethoxybenzene as an internal standard.

In order to circumvent these challenges in reductive aldehyde / alkyl halide couplings we envisioned developing a method to activate aldehydes as acyl anion equivalents. ${ }^{37-40}$ A key report from Ogoshi detailing the formation of alphasilyloxy Ni(II) complexes of type 1a (Scheme 1B) from
$\mathrm{Ni}(0)$ sources, aldehydes and silyl chlorides provided inspiration towards this goal. ${ }^{41}$ Indeed, Mackenzie ${ }^{42}$ and Weix ${ }^{8,43}$ have shown that similar allyl complexes derived from $\mathrm{Ni}(0)$, Michael acceptors and silyl chlorides undergo C-C coupling with appropriate organohalide sources. We hypothesized that the generation of this $\alpha$-silyloxy Ni-complex $\mathbf{1 b}$ (Scheme 1C) could be leveraged with known Ni-catalyzed cross-electrophile coupling reactions of unactivated $\mathrm{sp}^{3}$ halides to afford silyl-protected ether products. ${ }^{27}$

An initial screen of ligands commonly employed in reductive cross-couplings revealed $\mathrm{BiOX}$ as a uniquely promising candidate for selective coupling (see SI for more optimization details). In all reactions, competitive formation of the corresponding enol ether $\mathbf{3}$ and reduced silyl ether $\mathbf{4}$ in addition to homocoupling of the alkyl bromide was observed. Upon further screening we found that olefin additives could minimize the formation of these side products, while affording better mass balance and higher yields, with excellent reactivity observed when using 1,5-hexadiene. Further optimization revealed that when using $75 \mathrm{~mol} \%$ of this additive, in addition to $50 \mathrm{~mol} \%$ of $\mathrm{NaI}$, excellent yields of the desired cross-coupled product were obtained.

With optimized conditions in hand, we explored the scope of the reaction. Varying the aldehyde component revealed that the reaction tolerated a number of steric environments around the aldehyde coupling partner as well as chemoselective activation of the aldehyde (Scheme 2). Benzyl ethers and straight-chain aldehydes were shown to couple effectively. Substrates with $\beta$-branching, such as citronellal (7) and isovaleraldehyde (8), delivered the desired products in good yield. Aldehydes bearing protected amines such as carbamates were well tolerated, showing no activation or cleavage of the Boc group in 9. $\alpha$-Branched aldehydes showed comparable reactivity to linear substrates (10-13), however, aldehydes bearing $\alpha$-quaternary centers did not afford meaningful amounts of coupled product.

Alkyne functionality was also tolerated, affording modest yields of the carbonyl coupling. Additionally, decreased reactivity was observed when heteroatom functionality is located at the $\alpha$-position (16). The reaction displayed good reactivity for aldehydes, however ketones afforded minimal amounts of coupled products. Additionally, aryl aldehydes are incompatible with this coupling and afford no desired product at the expense of undesired pinacol coupling (see SI for details). ${ }^{41}$

Exploration of the scope of the alkyl bromide coupling partner displayed similarly broad functional group compatibility (Scheme 3). As a general note, while we found that the inclusion of NaI was beneficial during the initial optimization with ethyl 4-bromobutyrate this benefit was not always observed. In some cases, the inclusion of NaI led to decreased yields of the desired products. We attribute this to enhanced reactivity of certain alkyl iodide substrates generated from in-situ HalEx reactions (see SI for more discussion).

Esters, nitriles, and phosphonate ester functionality $(2,17-19)$ is well tolerated and afford high yields of coupled products, highlighting the mild nature of these conditions. Alkyl and aryl-chlorides $(\mathbf{2 0}, \mathbf{2 2})$ are not activated under these conditions, nor are boronate esters (23), offering 
further sites for derivatization via other cross-coupling systems. Ethers (24) and acetates (25) are coupled in excellent yields, allowing for polyol structures to be constructed.

\section{Scheme 2. Aldehyde Reaction Scope. ${ }^{a}$}
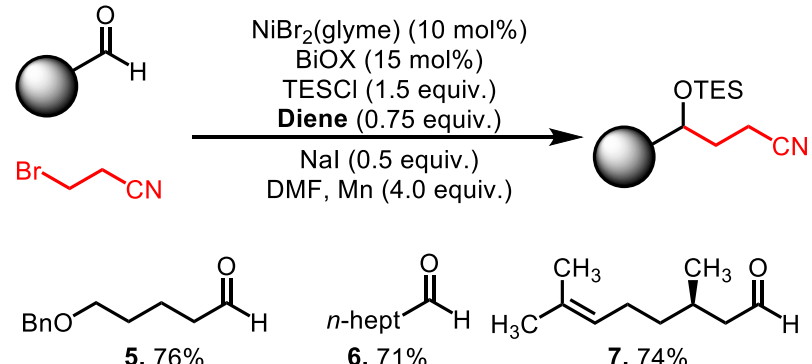<smiles>CC(C)CC=O</smiles>

$8,68 \%$<smiles>O=CC1CCCCC1</smiles>

$11,57 \%^{b}$

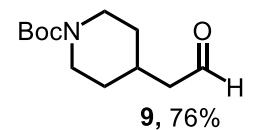<smiles>CCC(C)C=O</smiles>

$12,45 \%^{b}$<smiles>O=CCC(NC(=O)c1ccccc1)c1ccccc1</smiles>

$14,48 \%$ $1: 1$ d.r.

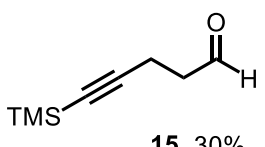

$15,30 \%$
$1: 1$ d.r.<smiles></smiles><smiles>O=CC1CCOCC1</smiles>

$13,56 \%^{b}$

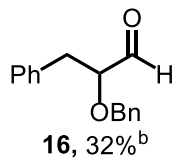

2: 1 d.r. a) General reaction conditions on a $0.5 \mathrm{mmol}$ scale: Aldehyde $(1.0$ equiv.), 3-bromopropionitrile (2.0 equiv.), $\mathrm{NiBr}_{2}$ (glyme) (10 mol\%), BiOX (15 mol\%), TESCl (1.5 equiv.), Diene (0.75 equiv.), NaI ( 0.5 equiv.), Mn (4.0 equiv.), DMF (1.0 mL). Yields refer to isolated yields; b) Reaction run without NaI.

Protected amine functional groups, such as trifluoroacetamides (26-27), sulfonamides (28) and carbamates (29) are also tolerated. Sterically encumbered bromides such as protected piperidine derivatives (30), isobutyl bromide (31) and cycloalkyl bromides (32) are competent coupling partners, albeit displaying diminished yields. Secondary bromides such as $\mathbf{3 0}$ and $\mathbf{3 2}$ could be coupled in moderate yields when $\mathrm{LiBr}$ is used in place of NaI. ${ }^{44}$

We also found that more activated olefins are not susceptible to competitive reactions under these conditions as evidenced by the clean coupling of substrate 33. Additionally, the geometric configuration of the olefin is maintained throughout the reaction, suggesting that $\beta$-hydride elimination or chain-walking processes related to activation of the bromide are slow in this catalytic system. Potentially Lewis acidic sensitive groups such as acetals (34) are also tolerated. Finally, heterocyclic functionality is tolerated, as evidenced by the clean participation of pyrimidine structures 35 and 36. Efficient coupling was also demonstrated on a $5.0 \mathrm{mmol}$ scale, obtaining coupled product 18 in slightly diminished yield (69\%).

We anticipated that the features of the reaction observed during our initial optimization, particularly the formation of enol ether $\mathbf{3}$ and silyl ether $\mathbf{4}$ (Table 1) may shed light on key intermediates in the catalytic pathway. Stoichiometric experiments revealed similar product distributions observed under the catalytic conditions. When using $\mathrm{Ni}(\operatorname{cod})_{2}$ and equivalent amounts of aldehyde and bromide, a $27 \%$ yield of the coupled product 2 was observed (Scheme 4A). In addition, undesired products $\mathbf{3}$ and $\mathbf{3 7}$ were also observed in $8 \%$ and $21 \%$ yield, respectively. Additionally, when $\alpha$-oxy aldehyde $\mathbf{1 6}$ was subjected to a stoichiometric reaction, enol ether 3 was observed in 52\% yield in addition to $50 \%$ yield of silyl ether $\mathbf{4 0}$. The formation of both of these species would be consistent with a sequence outlined in Scheme 4A wherein intermediate 40 undergoes $\beta$-oxy elimination to furnish $\mathbf{3}$, and the resulting nickel alkoxide $\mathbf{4 0}$ undergoes silylation with TESCl to furnish $\mathbf{3 8 .}$

\section{Scheme 3. Bromide Reaction Scope. ${ }^{\mathrm{a}}$}
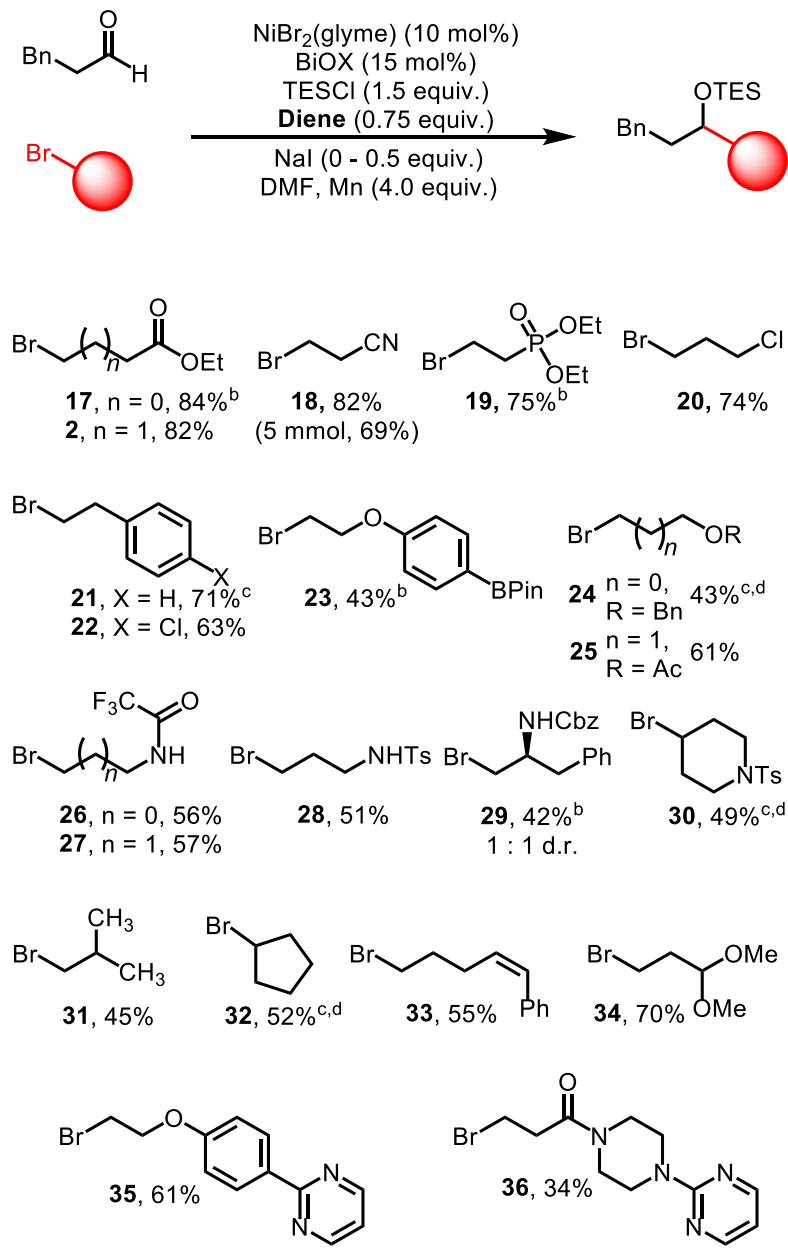

a) General reaction conditions on a 0.5 mmol scale: Dihydrocinnamaldehyde (1.0 equiv.), Alkyl Bromide (1.0 - 2.0 equiv.), $\mathrm{NiBr}_{2}$ (glyme) (10 mol\%), BiOX (15 mol\%), TESCl (1.5 equiv.), Diene ( 0.75 equiv.), NaI ( 0.5 equiv.), Mn (4.0 equiv.), DMF (1.0 mL). Yields refer to isolated yields; b) Reaction run without NaI; c) Reaction run with 1.0 equiv. LiBr instead of $\mathrm{NaI}$; d) Product isolated as the corresponding alcohol following TBAF deprotection.

The observation of $\mathbf{3}$ and $\mathbf{3 7}$ in both the stoichiometric experiments as well as the catalytic coupling conditions suggest a common mechanism for their formation. Control experiments confirmed that the aldehyde is only consumed when both Ni(II) salt and reductant are present (see SI for details). This observation is consistent with activation of the aldehyde via interaction with a low-valent Ni species. Additionally, when the silyl chloride is omitted, complete consumption of the aldehyde is observed to give a complex 
mixture, suggesting that the presence of silyl chloride leads to stabilization of a key intermediate leading to formation of the coupled product. Importantly, only trace enolization is observed when $\mathrm{Ni}$ is omitted from these reactions, ruling out a background silyl-mediated enolization as a pathway to generate $\mathrm{HCl}$, which could react to form a nickel hydride species.

Taken together, these results provide preliminary evidence for the formation of an $\alpha$-silyloxy $\mathrm{Ni}$ species under the reaction conditions. A catalytic cycle combining these

Scheme 4. Mechanistic Considerations and Catalytic Cycle.

\section{A) Stoichiometric Experiments}
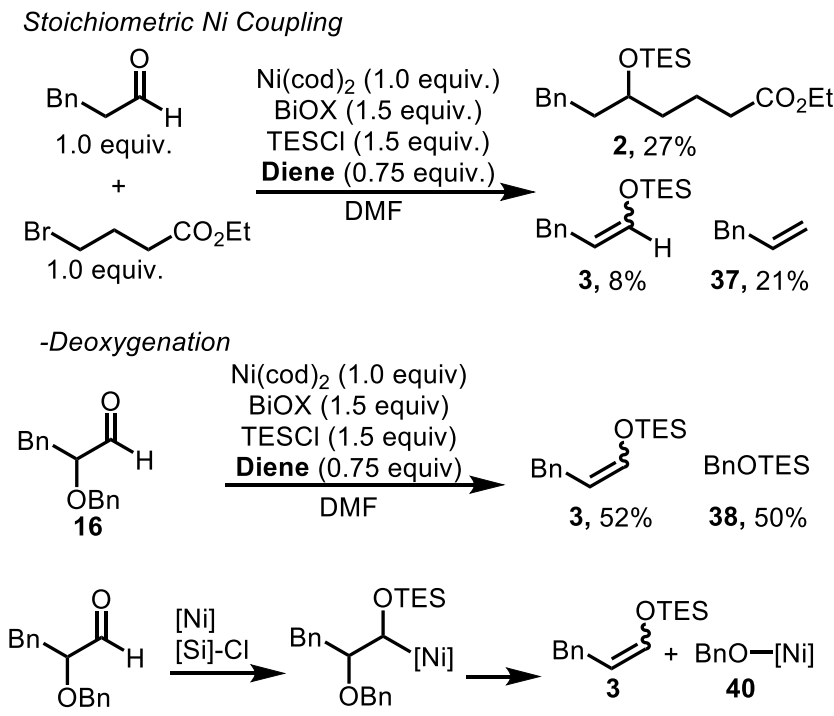

$$
\text { B) Proposed Mechanism }
$$

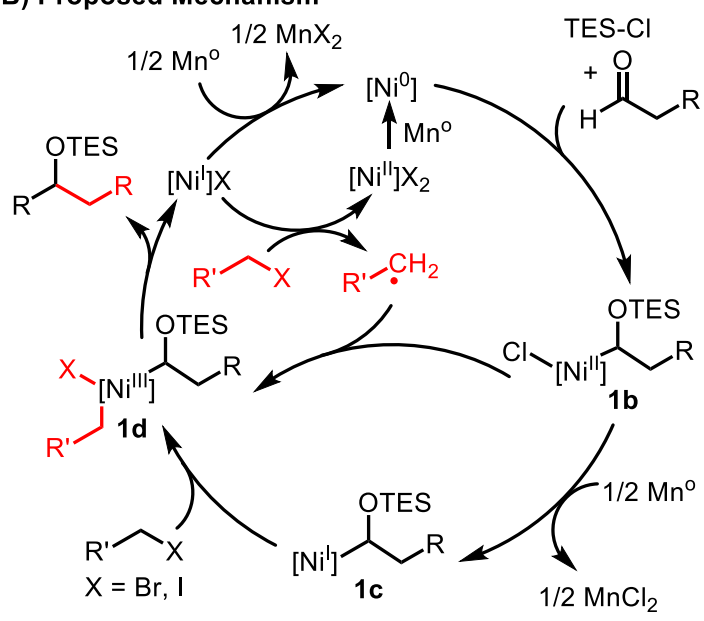

C) Pathways for Side-Product Formation -Hydride Elimination

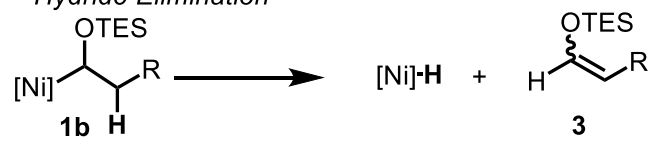

$\mathrm{Ni}-\mathrm{H}$ Deoxygenation

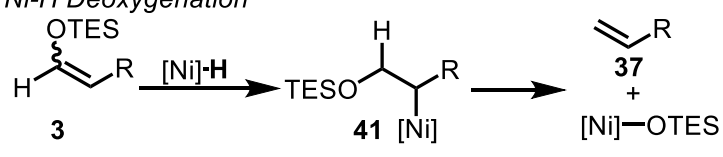

observations is shown in Scheme 4B. First, following reduction of the $\mathrm{Ni}(\mathrm{II})$ pre-catalyst, $\mathrm{Ni}(0)$ undergoes complexation with the aldehyde substrate and TESCl to furnish intermediate 1b. This intermediate can then engage the alkyl halide coupling partner either via a radical-chain process as noted by Weix ${ }^{27}$ or through a sequential reduction - oxidative addition pathway ${ }^{45}$. Regardless of the exact nature of this step, the resulting dialkyl Ni(III) intermediate can then undergo reductive elimination to furnish the coupled product and a $\mathrm{Ni}(\mathrm{I})$ salt. This $\mathrm{Ni}(\mathrm{I})$ salt can then either undergo reduction by $\mathrm{Mn}$ to regenerate the active $\mathrm{Ni}(0)$ catalyst or activate another equivalent of alkyl halide to further the radical chain process. A stoichiometric reaction between aldehyde and alkyl bromide, in the absence of TESCl, afforded only bromide dimer and did not form any cross-coupled alcohol product. This result is inconsistent with an alternative mechanism wherein an alkyl-Ni nucleophile forms and undergoes a formal migratory insertion with the aldehyde substrate to forge the $\mathrm{C}-\mathrm{C}$ bond. ${ }^{33}$

The formation of $\mathbf{3}$ and $\mathbf{4}$ can be explained via undesired side-pathways of silyloxy intermediates 1b or 1c (Scheme 4C). Beta-hydride elimination from any silyloxy-Ni intermediates would result in the formation of derivatives of $\mathbf{3}$ and a $\mathrm{Ni}-\mathrm{H}$ species. Reinsertion of this $\mathrm{Ni}-\mathrm{H}$ species into 3 can afford a new alkyl-Ni intermediate $\mathbf{4 1}$ poised to undergo $\beta$ oxy elimination to furnish allylbenzene $\mathbf{3 7}$ and a Ni-alkoxide. Furthermore, the Ni-H generated via beta-hydride elimination can alternatively reduce an equivalent of aldehyde which would lead to $\mathbf{4}$ observed in reaction mixtures. The role of 1,5-hexadiene in minimizing the formation of these side-products may play a role in suppressing the formation of $\mathrm{Ni}-\mathrm{H}$, acts as a sacrificial hydride acceptor, or simply stabilize the low-valent nickel intermediates involved. ${ }^{46,47}$ Further studies are underway to better understand the role of this additive.

In conclusion, an efficient reductive coupling of aliphatic aldehydes and unactivated alkyl halides has been developed. The process addresses a key limitation of prior methods, specifically the ability to introduce unactivated $\mathrm{C}\left(\mathrm{sp}^{3}\right)$ groups in both the aldehyde and alkyl halide reaction components. Additionally, the process tolerates a wide range of functionality and is amenable to larger scale syntheses. The reaction utilizes an air-stable Ni(II) pre-catalyst and easily synthesized BiOX ligand. Preliminary mechanistic experiments suggest a novel mechanism proceeding through a silyloxy-Ni intermediate that effectively engages a free radical derived from an alkyl halide. Efforts to expand the scope of coupling partners and devise more efficient catalytic systems are currently underway.

\section{ASSOCIATED CONTENT}

Supporting Information. Optimization tables, experimental data, copies of spectra. This material is available free of charge via the Internet at http://pubs.acs.org.

\section{AUTHOR INFORMATION}

Corresponding Author

* John Montgomery - Department of Chemistry, University of Michigan, 930 North University Avenue, Ann Arbor, Michigan, 
48108-1055, United States. orcid.org/0000-0002-2229-0585; E-mail: jmontg@umich.edu

\section{Authors}

Cole L. Cruz - Department of Chemistry, University of Michigan, 930 North University Avenue, Ann Arbor, Michigan, 48108-1055, United States.

\section{ACKNOWLEDGMENT}

The authors thank the National Science Foundation (CHE1954939) for support of this research. Dr. Jichao Xiao and Zhenning Li are also acknowledged for helpful discussions.

\section{REFERENCES}

(1) Lovering, F.; Bikker, J.; Humblet, C. Escape from Flatland: Increasing Saturation as an Approach to Improving Clinical Success. J. Med. Chem. 2009, 52 (21), 6752-6756. https://doi.org/10.1021/jm901241e.

(2) Brown, D. G.; Boström, J. Analysis of Past and Present Synthetic Methodologies on Medicinal Chemistry: Where Have All the New Reactions Gone?: Miniperspective. J. Med. Chem. 2016, 59 (10), 4443-4458. https://doi.org/10.1021/acs.jmedchem.5b01409.

(3) Schneider, N.; Lowe, D. M.; Sayle, R. A.; Tarselli, M. A.; Landrum, G. A. Big Data from Pharmaceutical Patents: A Computational Analysis of Medicinal Chemists' Bread and Butter. J. Med. Chem. 2016, 59 (9), 4385-4402. https://doi.org/10.1021/acs.jmedchem.6b00153.

(4) Moragas, T.; Correa, A.; Martin, R. Metal-Catalyzed Reductive Coupling Reactions of Organic Halides with CarbonylType Compounds. Chem. Eur. J. 2014, 20 (27), 8242-8258. https://doi.org/10.1002/chem.201402509.

(5) Chen, R.; Couming, V.; Guzowski, J.; Irdam, E.; Kiesman, W. F.; Kwok, D.-I. A.; Liang, W.; Mack, T.; O’Brien, E. M.; Opalka, S. M.; Patience, D.; Sahli, S.; Walker, D. G.; Osei-Yeboah, F.; Gu, C.; Zhang, X.; Stöckli, M.; Stucki, T.; Matzinger, H.; Kuhn, R.; Thut, M.; Grohmann, M.; Haefner, B.; Lotz, J.; Nonnenmacher, M.; Cerea, P. Synthesis of Vixotrigine, a Voltageand Use-Dependent Sodium Channel Blocker. Part 2: Development of a Late-Stage Process. Org. Process Res. Dev. 2020, 24 (12), 2814-2829. https://doi.org/10.1021/acs.oprd.0c00427.

(6) Nimmagadda, S. K.; Korapati, S.; Dasgupta, D.; Malik, N. A.; Vinodini, A.; Gangu, A. S.; Kalidindi, S.; Maity, P.; Bondigela, S. S.; Venu, A.; Gallagher, W. P.; Aytar, S.; González-Bobes, F.; Vaidyanathan, R. Development and Execution of an $\mathrm{Ni}(\mathrm{II})$-Catalyzed Reductive Cross-Coupling of Substituted 2-Chloropyridine and Ethyl 3-Chloropropanoate. Org. Process Res. Dev. 2020, 24 (6), 1141-1148. https://doi.org/10.1021/acs.oprd.0c00134.

(7) Swyka, R. A.; Zhang, W.; Richardson, J.; Ruble, J. C.; Krische, M. J. Rhodium-Catalyzed Aldehyde Arylation via FormateMediated Transfer Hydrogenation: Beyond Metallic Reductants in Grignard/Nozaki-Hiyami-Kishi-Type Addition. J. Am. Chem. Soc. 2019, 141 (5), 1828-1832. https://doi.org/10.1021/jacs.8b13652.

(8) Garcia, K. J.; Gilbert, M. M.; Weix, D. J. Nickel-Catalyzed Addition of Aryl Bromides to Aldehydes To Form Hindered Secondary Alcohols. J. Am. Chem. Soc. 2019, 141 (5), 18231827. https://doi.org/10.1021/jacs.8b13709.

(9) Ni, S.; Garrido-Castro, A. F.; Merchant, R. R.; de Gruyter, J. N.; Schmitt, D. C.; Mousseau, J. J.; Gallego, G. M.; Yang, S.; Collins, M. R.; Qiao, J. X.; Yeung, K.-S.; Langley, D. R.; Poss, M. A.; Scola, P. M.; Qin, T.; Baran, P. S. A General Amino Acid Synthesis Enabled by Innate Radical Cross-Coupling. Angew. Chem. Int. Ed. 2018, 57 (44), 14560-14565. https://doi.org/10.1002/anie.201809310.
Ni, S.; Padial, N. M.; Kingston, C.; Vantourout, J. C.; Schmitt, D. C.; Edwards, J. T.; Kruszyk, M. M.; Merchant, R. R.; Mykhailiuk, P. K.; Sanchez, B. B.; Yang, S.; Perry, M. A.; Gallego, G. M.; Mousseau, J. J.; Collins, M. R.; Cherney, R. J.; Lebed, P. S.; Chen, J. S.; Qin, T.; Baran, P. S. A Radical Approach to Anionic Chemistry: Synthesis of Ketones, Alcohols, and Amines. J. Am. Chem. Soc. 2019, 141 (16), 67266739. https://doi.org/10.1021/jacs.9b02238.

(11) Majumdar, K. K.; Cheng, C.-H. Ni(II)/Zn-Mediated Chemoselective Arylation of Aromatic Aldehydes: Facile Synthesis of Diaryl Carbinols. Org. Lett. 2000, 2 (15), 2295-2298. https://doi.org/10.1021/ol006064w.

(12) Heinz, C.; Lutz, J. P.; Simmons, E. M.; Miller, M. M.; Ewing W. R.; Doyle, A. G. Ni-Catalyzed Carbon-Carbon BondForming Reductive Amination. J. Am. Chem. Soc. 2018, 140 (6), 2292-2300. https://doi.org/10.1021/jacs.7b12212.

(13) Gu, J.; Wang, X.; Xue, W.; Gong, H. Nickel-Catalyzed Reductive Coupling of Alkyl Halides with Other Electrophiles: Concept and Mechanistic Considerations. Org. Chem. Front. 2015, 2 (10), 1411-1421. https://doi.org/10.1039/C5Q000224A.

(14) Choi, H.; Nakajima, K.; Demeke, D.; Kang, F.-A.; Jun, H.-S.; Wan, Z.-K.; Kishi, Y. Asymmetric Ni(II)/Cr(II)-Mediated Coupling Reaction: Catalytic Process. Org. Lett. 2002, 4 (25), 4435-4438. https://doi.org/10.1021/ol026981x.

(15) Tan, Z.; Wan, X.; Zang, Z.; Qian, Q.; Deng, W.; Gong, H. NiCatalyzed Asymmetric Reductive Allylation of Aldehydes with Allylic Carbonates. Chem. Commun. 2014, 50 (29), 3827-3830. https://doi.org/10.1039/C3CC49859J.

(16) Fürstner, A.; Shi, N. Nozaki-Hiyama-Kishi Reactions Catalytic in Chromium. J. Am. Chem. Soc. 1996, 118 (49), 12349-12357. https://doi.org/10.1021/ja9625236.

(17) Fürstner, A. Carbon-Carbon Bond Formations Involving Organochromium(III) Reagents. Chem. Rev. 1999, 99 (4), 991-1046. https://doi.org/10.1021/cr9703360.

(18) Namba, K.; Kishi, Y. New Catalytic Cycle for Couplings of Aldehydes with Organochromium Reagents. Org. Lett. 2004, 6 (26), 5031-5033. https://doi.org/10.1021/ol047661b.

(19) Namba, K.; Wang, J.; Cui, S.; Kishi, Y. Surprisingly Efficient Catalytic Cr-Mediated Coupling Reactions. Org. Lett. 2005 7 (24), 5421-5424. https://doi.org/10.1021/ol052085k. Wessjohann, L. A.; Schrekker, H. S. Takai-Utimoto Reactions of Oxoalkylhalides Catalytic in Chromium and Cobalt. Tetrahedron Letters 2007, 48 (25), 4323-4325. https://doi.org/10.1016/j.tetlet.2007.04.119.

(21) Montgomery, J. Organonickel Chemistry. In Organometallics in Synthesis; Lipshutz, B. H., Ed.; John Wiley \& Sons, Inc.: Hoboken, NJ, USA, 2013; pp 319-428. https://doi.org/10.1002/9781118651421.ch3.

(22) Krug, C.; Hartwig, J. F. Direct Observation of Aldehyde Insertion into Rhodium-Aryl and -Alkoxide Complexes. J. Am. Chem. Soc. 2002, 124 (8), 1674-1679. https://doi.org/10.1021/ja017401e.

(23) Verheyen, T.; van Turnhout, L.; Vandavasi, J. K.; Isbrandt, E. S.; De Borggraeve, W. M.; Newman, S. G. Ketone Synthesis by a Nickel-Catalyzed Dehydrogenative Cross-Coupling of Primary Alcohols. J. Am. Chem. Soc. 2019, 141 (17) 6869-6874. https://doi.org/10.1021/jacs.9b03280.

(24) Zheng, Y.-L.; Newman, S. G. Cross-Coupling Reactions with Esters, Aldehydes, and Alcohols. Chem. Commun. 2021, 57 (21), 2591-2604. https://doi.org/10.1039/D0CC08389E. Weix, D. J. Methods and Mechanisms for Cross-Electrophile Coupling of Csp ${ }^{2}$ Halides with Alkyl Electrophiles. Acc. Chem. Res. 2015, 48 (6), 1767-1775. https://doi.org/10.1021/acs.accounts.5b00057.

(26) Kaga, A.; Chiba, S. Engaging Radicals in Transition MetalCatalyzed Cross-Coupling with Alkyl Electrophiles: Recent 
Advances. ACS Catal. 2017, 7 (7), 4697-4706. https://doi.org/10.1021/acscatal.7b01405.

Everson, D. A.; Weix, D. J. Cross-Electrophile Coupling: Principles of Reactivity and Selectivity. J. Org. Chem. 2014, 79 (11), 4793-4798. https://doi.org/10.1021/jo500507s.

(28) For examples of Cr-catalyzed couplings of alkyl halides using Co co-catalysis see refs. $18-20$. In refs. 18 and 19 only a single example is shown coupling 1-iodohexane and dihydrocinnamaldehyde in excellent yield (83\%). In ref. 20 , a single example is shown coupling ethyl 1-iodohexanoate and dihydrocinnamaldehyde in up to $56 \%$ yield. During the preparation of this manuscript, Baran reported an electrochemical $\mathrm{Cr}$-catalyzed version of the reaction reported in ref. 10 demonstrating 2 examples of couplings with aliphatic aldehydes. Gao, Y.; Hill, D. E.; Hao, W.; McNicholas, B. J.; Vantourout, J. C.; Hadt, R. G.; Reisman, S. E.; Blackmond, D.; Baran, P. S. Electrochemical NozakiHiyama-Kishi Coupling: Scope, Applica- Tions, and Mechanism. ChemRxi Preprint. https://doi.org/10.26434/chemrxiv.14251787.v1.

(29) Zhang, X.; MacMillan, D. W. C. Direct Aldehyde C-H Arylation and Alkylation via the Combination of Nickel, Hydrogen Atom Transfer, and Photoredox Catalysis. J. Am. Chem. Soc. 2017, 139 (33), 11353-11356. https://doi.org/10.1021/jacs.7b07078.

(30) Wotal, A. C.; Weix, D. J. Synthesis of Functionalized Dialkyl Ketones from Carboxylic Acid Derivatives and Alkyl Halides. Org. Lett. 2012, 14 (6), 1476-1479. https://doi.org/10.1021/ol300217x.

(31) Wang, J.; Hoerrner, M. E.; Watson, M. P.; Weix, D. J. NickelCatalyzed Synthesis of Dialkyl Ketones from the Coupling of N-Alkyl Pyridinium Salts with Activated Carboxylic Acids. Angew. Chem. Int. Ed. 2020, 59 (32), 13484-13489. https://doi.org/10.1002/anie.202002271.

(32) Kakeno, Y.; Kusakabe, M.; Nagao, K.; Ohmiya, H. Direct Synthesis of Dialkyl Ketones from Aliphatic Aldehydes through Radical $N$-Heterocyclic Carbene Catalysis. ACS Catal. 2020, 10 (15), 8524-8529. https://doi.org/10.1021/acscatal.0c02849.

(33) Börjesson, M.; Moragas, T.; Gallego, D.; Martin, R. MetalCatalyzed Carboxylation of Organic (Pseudo)Halides with $\mathrm{CO}$ 2. ACS Catal. 2016, 6 (10), 6739-6749. https://doi.org/10.1021/acscatal.6b02124.

(34) Börjesson, M.; Moragas, T.; Martin, R. Ni-Catalyzed Carboxylation of Unactivated Alkyl Chlorides with $\mathrm{CO}_{2}$. J. Am. Chem. Soc. 2016, 138 (24), 7504-7507. https://doi.org/10.1021/jacs.6b04088.

(35) Juliá-Hernández, F.; Moragas, T.; Cornella, J.; Martin, R. Remote Carboxylation of Halogenated Aliphatic Hydrocarbons with Carbon Dioxide. Nature 2017, 545 (7652), 8488. https://doi.org/10.1038/nature22316.

(36) Serrano, E.; Martin, R. Nickel-Catalyzed Reductive Amidation of Unactivated Alkyl Bromides. Angew. Chem. Int.
Ed. 2016, $55 \quad$ (37), 11207-11211. https://doi.org/10.1002/anie.201605162.

(37) Kondo, Y.; Nagao, K.; Ohmiya, H. Reductive Umpolung for Asymmetric Synthesis of Chiral $\alpha$-Allenic Alcohols. Chem. Commun. 2020, 56 (54), 7471-7474. https://doi.org/10.1039/D0CC02619K.

(38) Takeda, M.; Mitsui, A.; Nagao, K.; Ohmiya, H. Reductive Coupling between Aromatic Aldehydes and Ketones or Imines by Copper Catalysis. J. Am. Chem. Soc. 2019, 141 (8), 3664-3669. https://doi.org/10.1021/jacs.8b13309.

(39) Takeda, M.; Yabushita, K.; Yasuda, S.; Ohmiya, H. Synergistic Palladium/Copper-Catalyzed Csp ${ }^{3}$-Csp ${ }^{2}$ Cross-Couplings Using Aldehydes as Latent $\alpha$-Alkoxyalkyl Anion Equivalents. Chem. Commun. 2018, 54 (50), 6776-6779. https://doi.org/10.1039/C8CC01055B.

(40) Wang, L.; Lear, J. M.; Rafferty, S. M.; Fosu, S. C.; Nagib, D. A. Ketyl Radical Reactivity via Atom Transfer Catalysis. Science 2018, 362 (6411), 225-229. https://doi.org/10.1126/science.aau1777.

(41) Ogoshi, S.; Kamada, H.; Kurosawa, H. Reaction of (H2-Arylaldehyde)Nickel(0) Complexes with Me3SiX (X=0Tf, $\mathrm{Cl}$ ). Application to Catalytic Reductive Homocoupling Reaction of Arylaldehyde. Tetrahedron 2006, 62 (32), 75837588. https://doi.org/10.1016/j.tet.2006.03.124.

(42) Johnson, J. R.; Tully, P. S.; Mackenzie, P. B.; Sabat, M. A Practical Reversed-Polarity Alternative to Organocuprate Conjugate Addition Chemistry. Halocarbon Coupling Reactions of Enal- and Enone-Derived Allylnickel Reagents. J. Am. Chem. Soc. 1991, 113 (16), 6172-6177. https://doi.org/10.1021/ja00016a037.

(43) Huihui, K. M. M.; Shrestha, R.; Weix, D. J. Nickel-Catalyzed Reductive Conjugate Addition of Primary Alkyl Bromides to Enones To Form Silyl Enol Ethers. Org. Lett. 2017, 19 (2), 340-343. https://doi.org/10.1021/acs.orglett.6b03509.

(44) Huang, L.; Olivares, A. M.; Weix, D. J. Reductive Decarboxylative Alkynylation of $N$-Hydroxyphthalimide Esters with Bromoalkynes. Angew. Chem. Int. Ed. 2017, 56 (39), 11901-11905.

https://doi.org/10.1002/anie.201706781.

(45) Diccianni, J. B.; Diao, T. Mechanisms of Nickel-Catalyzed Cross-Coupling Reactions. Trends in Chemistry 2019, 1 (9), $830-844$ https://doi.org/10.1016/j.trechm.2019.08.004.

(46) Wu, J.; Faller, J. W.; Hazari, N.; Schmeier, T. J. Stoichiometric and Catalytic Reactions of Thermally Stable Nickel(0) NHC Complexes. Organometallics 2012, 31 (3), 806-809. https://doi.org/10.1021/om300045t.

(47) Nett, A. J.; Montgomery, J.; Zimmerman, P. M. Entrances, Traps, and Rate-Controlling Factors for Nickel-Catalyzed C-H Functionalization. ACS Catal. 2017, 7 (10), 7352 7362. https://doi.org/10.1021/acscatal.7b02919. 